\title{
Driving IS value creation by knowledge capturing. Theoretical aspects and empirical evidences
}

Track: Organizational change and impact of IT

\begin{abstract}
Business process change and information systems development are usually associated in best business practices. However, it is not ever clear if the quality of business process change really impact on quality and value of information systems.

To realize value from business process change through information systems quality, it is necessary to clearly define an improvement strategy regarding both business activities and operations and the IT applications embedding them.

Davenport [2] identified three most important key factors driving IS value, deriving from business process change: integrate, optimize and informate. Integrate means to keep together large companies, with several different business units, operating all over the world. Optimize means to use business process change and IT applications development and implementation to perform more efficient and effective business activities and operations. Informate means to collect process and distribute information where, when and how users need it, supplying information services at managed cost and better quality.

We suggest to add a key factor driving IS value deriving from business process change : Identify Knowledge. Identify Knowledge, means to identify knowledge, when and how users need it, improving services and process decision. Information Technologies bear the potential of new uses. These uses provoke a new organisation which induces a new vision of IS strategy. Under the influence of globalization, and the impact of Information and Communication Technologies (ICT) that radically modify our relationship with space and time, the hierarchical company locked up on its local borders becomes an Extended Company, without borders, opened and adaptable. In this context, this paper proposes a shift in the way the design of Information Systems is viewed based on business process. The approach adopted is a global philosophy based on business process management within the framework of all the methodological principles.

Empirical evidences are available, by an Italian large company, using business process management and knowledge capturing as an improvement strategy for IS value. This company defined a well conceived framework to realize the better quality of both business processes and IT applications, aiming to implement ongoing IS management activities, to continuously produce value from IS. This frame-
\end{abstract}


work is based both on BPM and on knowledge identification like instruments to improve the value of information systems and the quality of business processes.

\section{Introduction}

In this paper, we suggest to add a key factor driving Information System (IS) value deriving from business process change, thanks to knowledge capturing within a project of development of a unified information system. In the following section, we propose a method to identify company group knowledge used within a project regarding information systems governance, to be transferred and applied to all the companies of a corporation. Then we present an empirical evidence using $\mathrm{BPM}$ as an improvement strategy for IS value. In the fourth and fifth sections we present an example using BPM in Finmeccanica and solutions and instruments of BPM in Finmeccanica. We conclude with the expected benefits.

\section{A method to identify company group knowledge}

In this section we propose a methodology to evaluate knowledge capturing within a project of development of a unified information system. This methodology is composed of three phases (i) Determining "Reference Crucial Knowledge" (ii) Constructing Preference model and (iii) Classifying "Potential Crucial Knowledge".

The first phase regards constructive learning devoted to infer the preference model of decision makers. Practically, it consists in inferring a set of decision rules from some holistic information in terms of assignment examples provided by

the decision makers. This is done through the DRSA (Dominance-based Rough Set Approach) [3]. This method is an extension of rough set theory [7]. The previous set of rules may be used in the same project or in other similar projects. This phase includes also the identification, using GAMETH ${ }^{\circledR}$ [4], of a set of reference crucial knowledge. We have adapted the GAMETH ${ }^{\circledR}$ Framework [6] to construct reference crucial knowledge. Thus, we identify only one sensitive process and critical activities related to that process, and we clarify the need of knowledge to solve problems related to critical activities.

The used approach includes three steps. First, we identify the sensitive processes with the leaders. These processes will be the object of an in-depth analysis. The second step consists, on the one hand, in modelling the identified sensitive processes and on the other hand, in analyzing critical activities associated to a sensitive process. The third step consists of identifying knowledge. 
The second phase includes the construction of preference model and the evaluation of knowledge with the respect to a convenient set of criteria. Three subfamilies of criteria were constructed: (i) knowledge vulnerability family that are devoted to measure the risk of knowledge loss and the cost of its (re)creation, (ii) knowledge role family that are used to measure the contribution of the piece of knowledge to the project objectives, and (iii) use duration family that is devoted to measure the use duration of the knowledge based on the company average and long term objectives.

Once all knowledge items are evaluated with respect to all criteria, an iterative procedure is applied aiming at jointly inferring the decision rules. Two decision classes are defined C11: "non crucial knowledge" and C12: "crucial knowledge".

In the third phase, the decision maker uses the decision rules of the different decision makers defined in the second phase to assign the new knowledge which is called potential crucial knowledge, to the classes $\mathrm{Cl1}$ or $\mathrm{Cl} 2$.

More specifically, a multi-criteria classification of potential crucial knowledge is performed on the basis of the decision rules that have been collectively identified by the decision maker(s) in the second phase. The term of potential crucial knowledge refers to the knowledge that has been temporarily identified as crucial by at least one decision maker. The generated potential crucial knowledge are analyzed and then evaluated against the criteria identified in the second phase. Then, they are assigned in one among the two decision classes $\mathrm{Cl1}$ or $\mathrm{Cl} 2$.

\section{Empirical evidences: using BPM as an improvement strategy for IS value}

Finmeccanica is the main Italian industrial group operating globally in the aerospace, defence and security sectors, and is one of the world's leading groups in the fields of helicopters and defence electronics. It is also the European leader for satellite and space services as well as having considerable know-how and production capacity in the energy and transport fields. Headquartered in Italy and with a vast industrial base in the UK as well as important production facilities in the rest of Europe and in the USA, Finmeccanica has a workforce of more than 73,056 people, and a revenues volume of euro mil. 18,176 (source: Finmeccanica Company Profile).

The company's vision is mainly based on the idea that their own future lies in creating a single identity for all the companies belonging to the group, regardless on their geographical location or their business activities. ICT and information systems are important leverages to support both integration and internalization processes[5].

To pursue these goals, ICT governance has been assigned to a single company, Finmeccanica Group Service ICT (FNM ICT), with the mission to build a general framework for information systems governance to be applied to all the companies of the group, all over the world. 
FNM ICT defined three main ways to realize its own mission:

- process standardization and optimization, to share common operations, activities and business practices all over the group and therefore to create an unified information system, able to integrate both business processes and information;

- ICT service improvement to business, to increase the effectiveness of ICT investments for business performance;

- Knowledge management and sharing, to create a single firm grouping all the Finmeccanica companies and to leverage the role of information and knowledge in business management.

To support its own ICT strategy, FNM ICT implemented a business change framework, based on Business Process Management, aiming to integrate, optimize and informate business processes thanks to the development and configuration of harmonized ICT applications. A central role in this framework is played by knowledge capturing, to support the quality of business processes, ICT services and information all over the group.

In further paragraphs, we would analyze scope, solutions and benefits deriving from the use of this framework in a global extended company.

\section{Scope of BPM in Finmeccanica}

As the main strategic goal of Finmeccanica is to create a single company, the integration of Information Systems has a very large scope: it interests all the companies belonging to the group. In the meantime, to integrate could become also to optimize both the business practices and the ICT cost and investments. Indeed, cost could be optimised thanks to the streamlining of ICT resources, realizing positive synergies thanks to centralised ICT governance and management; investments could be optimised by processes and applications standardization and reuse of both business practices and ICT platforms. The role of knowledge capturing is crucial to support processes optimisation, in order to share best practices all over the group.

Finmeccanica is a very large and global company; its present situation is the result of several mergers and acquisitions made in recent years, so that it is crucial for Finmeccanica to pursue a consolidation of all the businesses and production locations, especially outside Italy. FNM ICT decided to use Business Process Management Tools to achieve single prefixed goals and supply to the Operative Companies of the Group competences, methodologies and tools developed for ICT management in order to extend to every process the obtainable benefits deriving from standardization and integration. Finmeccanica decided to apply a meth- 
odology based on knowledge capturing, to identify sensitive processes, to model them and to share processes and knowledge across the corporation.

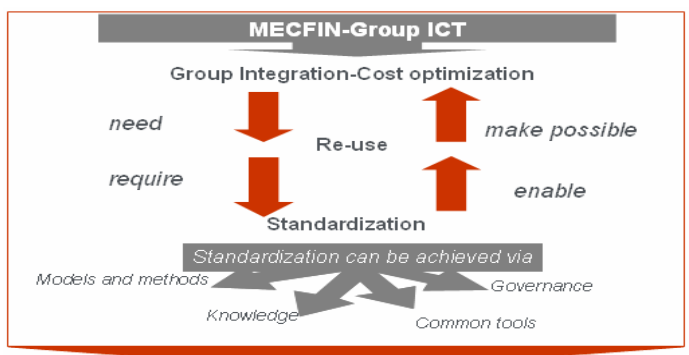

Fig. 1: BPM and ICT efficiency and effectiveness in Finmecanica

In Fig. 1 we can see a schema illustrating a virtuous cycle able to sustain both qualitative improvements in ICT and information systems, and quantitative benefits, especially deriving from rationalization of ICT resources. It is composed by several steps, linked each others and aiming both at ICT cost savings and ICT services quality.

1. For the first, group integration should be considered the main organizational goal to be reached, also by the contribute of ICT. It needs to integrate ICT applications and processes and permits to re-use ICT applications and business processes analysis and design across the group and all the companies.

2. To re-use applications and organizational design, standardization is necessary, to link each others harmonised processes and to implement the same ICT solutions all over the group.

3. Standardisation enables re-use, because processes are integrated and ICT applications are easy to implement to well-conceived and formalised business processes; all the companies and business units can save money not only by applications re-use, but especially by reducing business process analysis and redesign.

4. Process standardisation and ICT applications re-use make possible cost savings, especially for not-added-value ICT activities, such as software customisation and business processes changes. Well conceived ICT applications, designed on formalised and optimised business processes, could supply better information services and increase ICT effectiveness for business purposes.

\section{Solutions and instruments of BPM in Finmeccanica}

To realise the project described above, FNM ICT based its own work on four pillars:

- Governance; 
- Common tools;

- Models and Methods;

- Knowledge.

We want to focus especially on Models and Methods and Knowledge, to demonstrate how processes analysis and knowledge capturing are the key instruments by which to reach success of this initiative.

Indeed, FNM ICT built its roadmap on two linked activities:

- $\quad$ an in-depth analysis of business processes, to understand what to do and how to do, supported by process modelling using ARIS;

- $\quad$ an identification of crucial knowledge to be shared across the companies, to reach the best results from ICT applications applied to business management and decisions.

These practices aimed to identify the best operations and activities, to capture the knowledge on which they are based, and to translate these operations and knowledge in shared ICT applications, the same all over the group and (perhaps) the best for the strategic goals of Finmeccanica. To reach this result, an Application Management Activity has been designed, to realize implementation of best practice and knowledge in software. Applications Management Activity is then conceived as an iterative procedure, to identify also potential crucial knowledge to be collected and shared among all the business units.

To better apply its integration strategy regarding Information Systems, FNM ICT developed a set of instruments to be applied to a well-defined set of business goals. The instruments are:

- a set of Governance Policies, to integrate and centralise business processes regarding IT and Information Systems;

- a centralised ICT Initiatives Management, to govern new investments and ICT projects in order to consolidate the company's information systems in the future;

- a Master Service Agreement for outsourcing, to grant the same services quality for all the businesses;

- a Redesign Support based on BPM, aiming to effective business process reengineering, applying formalised instruments able to produce processes documentation and knowledge collection about business practices.

Regarding the use of BPM, Finmeccanica developed a framework for Application Management Activities, to support all the business units to optimised each own application portfolio, applying standardisation and re-use and finally gaining both ICT cost savings and ICT services quality and effectiveness. The Application Management activities are listed below.

\subsection{Integrate design and process avoiding incorrect implementation.}


To support this important goal, Finmeccanica developed a platform, made by several instruments such as: a list of universal business activities, a predefined business modelling knowledge base, a set of workflow models and the design policies to be applied by all the business units belonging to Finmeccanica. All these instruments are able to assure that business processes could be designed applying a common framework and preparing in this way a standardised business process view able to be implemented by re-use software applications.

\subsection{Take advantages of Process-Orientation avoiding consulting \& design ex- tra-cost.}

One of the more expensive activities in business process analysis and software design and implementation is consulting. Thanks to a standardised method to analyse business processes and a shared knowledge base of ICT projects, business units can avoid the work of consultants and re-use business processes analysis made by others business units in the group. It requires transparency of the contents of ICT projects and understandable documentation, but these requirements in the meantime improve also the probability of success of ICT projects.

\subsection{Process-oriented implementation \& Execution avoiding inefficient devel- opment}

The analysis of business processes is the basis for the further development and/or implementation of ICT application standardised, well integrated, based on an unique database and optimised in quality and service effectiveness. To support the development and implementation processes, Finmeccanica arranged a platform based on three phases: business processes definition, based on shared processes analysis and knowledge; ICT applications development; processes execution, based on ICT applications and applying standard business processes performance metrics, to support both internal and external benchmarking on business processes quality and efficiency.

\subsection{Support Process Integration Challenges with Enterprise architectures avoiding spaghetti like systems}

Business processes standardisation and implementation produce also the integration of ICT applications, platform and interfaces. The final result is a more rationalised ICT architecture, with streamlining of resources, better technological performs and savings to be addressed to value added ICT project, instead of to ICT infrastructure.

\section{Expected benefits}

BPM and knowledge capturing as support for better ICT solutions could really be the source of important benefits both for ICT investments returns and for busi- 
ness value creation. In Finmeccanica, the main goal of BPM was to support business integration, to help the company to really merge all the business units in a unique firm, with shared strategies, values and performance. In the meantime, Finmeccanica decided to apply BPM and knowledge capturing also to improve processes quality and to support better ICT investments, thanks to several ICT value drivers:

- lower cost in application implementations;

- $\quad$ savings in ICT architectures;

- $\quad$ streaming of ICT resources;

- $\quad$ ICT applications reuse;

- processes optimisation and ICT effectiveness;

- crucial knowledge sharing.

One of the more interesting effects of this ICT governance framework is the use of savings deriving from ICT efficiency and applications reuse: indeed, the company decided to invest such savings in capital expenditure regarding value added ICT initiatives. In this way, maintaining the same ICT budget, money was moved from operational expenditure to ICT investments for strategic purpose [8].

However, it is important to note also that knowledge capturing produces intangibles effects on the Information Systems; in Finmeccanica, these effects are linked with re-documentation of business processes and applications. Indeed, this methodology produces a formalisation and visualization of business processes, improving the knowledge of business activities and operations. Moreover, this knowledge is shared and collected by a database open to all the business units of Finmeccanica and it permits analysis, comparison and benchmarking of business processes and applications on different sites and companies of the group.

\section{Reference}

1. Belton, V. and J. Pictet, 'A framework for group decision using a MCDA model: sharing, aggregation or comparing individual information', Journal of Decision Systems, 6(3), 283-303, 1997.

2. Davenport T., J. Harris and S. Cantrell. Enterprise systems and ongoing process change Business Process Management Journal 10(1), 16-26, 2004.

3. Greco, S., B. Matarazzo and R. Slowinski, Rough sets theory for multicriteria decision analysis. European Journal of Operational Research, 129, 1-47, 2001.

4. Grundstein, M. Rosenthal-Sabroux C and Pachulski A. Reinforcing Decision Aid By Capitalizing On Company's Knowledge. European Journal of Operational Research 14(5), 256-272, 2006.

5. Rosenthal-Sabroux C. and V. Thion-Goasdoué. A first step towards evaluating business process quality using a structural analysis of a social network, INFORSID, p.177-192, 2010.

6. Saad, I., C. Rosenthal-Sabroux and M. Grundstein. Improving the Decision Making Process in The Design project by Capitalizing on Company's Crucial Knowledge. Group Decision and Negotiation, 14, 131-145, 2005. 
7. Pawlak, Z. Rough sets, International Journal of Information \& Computer Sciences 11, pp.341-356, 1982.

8. Dameri R.P., Privitera S., IT Governance. Franco Angeli, Milano 2009. 